\title{
The Design and Publication of iBooks Author Conference Interpreting Course-Books in the Age of Big Data
}

\author{
Wensheng Xu*, Cheng Ye \\ Department of English, School of Foreign Languages, Tongji University, Shanghai, China \\ Email address: \\ xws $a$ tongji.edu.cn (Wensheng Xu), TobyYE1108@outlook.com (Cheng Ye) \\ ${ }^{*}$ Corresponding author
}

To cite this article:

Wensheng Xu, Cheng Ye. The Design and Publication of iBooks Author Conference Interpreting Course-Books in the Age of Big Data. International Journal of Language and Linguistics. Vol. 7, No. 2, 2019, pp. 63-68. doi: 10.11648/j.ij11.20190702.12

Received: February 15, 2019; Accepted: March 18, 2019; Published: April 10, 2019

\begin{abstract}
In the age of Big Data, the heterogeneous omnimedia conference interpreting (CI) books are introduced into the design and publication of the $\mathrm{CI}$ course-books by providing the learners with enormous amount of bilingual information and an interactive reading mode in accordance with their cognitive patterns. The present paper sets forth the four modern features of the iBooks Author (iBA) CI course-books with the prominence to the development of the self-formed mode of independent learning and CI learning strategies, and, on the strength of the well-accepted evaluation system, assesses the performance of this new kind of CI course-books through questionnaires and interviews with 57 candidates for the degree of Master of Translation and Interpreting (MTI) and some teachers in two Chinese universities. According to the results which prove the efficiency and advantages of iBA CI course-books in future CI teaching, the present paper suggests that iBA, an e-book authoring application, may well overcome the buckets effect of the traditional CI course-books, namely the cumbersome publication and time-consuming selection of suitable teaching materials, and thus it meets the talent market's need for more qualified conference interpreters and contributes to professional, customized CI skill development and practice on account of its sound theoretical basis, advanced teaching methods and scientific evaluation system.
\end{abstract}

Keywords: iBooks Author, Conference Interpreting Course-Books, Evaluation System

\section{Introduction and Literature Review}

In the age of Big Data, conference interpreting (hereinafter referred to as $\mathrm{CI}$ ) learning and practice, two processes that entail fragmented learning and up-to-the-minute teaching materials, call for a new philosophy of course-book compilation to deal with the challenges brought by emerging teaching modes such as MOOC, Flipped Classroom, iTunes U, Khan Academy and Microlecture. Surrounded by tremendous amounts of bilingual information in this age, CI learners and teachers, however, often cannot find suitable course-books. As a result, CI course-book compilers are facing pressing issues of how to collect target information, to compile CI course-books with characteristics of the age of Big Data that cater for the talent market, and to improve the efficiency of CI self-learning.

The compilation of the CI course-books has a direct bearing on CI's disciplinary development as it serves as a significant vehicle for CI teaching [1]. Currently, many scholars and researchers have proposed changes to the design of the CI course-books from different aspects. For example, the philosophy of the compilation should tend to be novel and put the learners first in order to encourage the dual-subject interaction [2]; with the deepening of the notion of "learner-centeredness", the new generation of CI course-books should emphasize the importance of the learners' self-learning, and should especially give full play to the various attributes of the Internet [3]; to create the "added value" of the CI teaching, the theory of "incremental realism" should not fail to play a part in introducing the learners to the real interpreting conditions [4]; for the sake of processing teaching materials and thereby maximizing the teaching quality, the new CI course-books have the option of multimodal interpreting corpora [5]; in consideration of the surging demand of the wider civil society for interpreters of different levels, the principle of developing CI course-books in the near future should be profession-oriented [6]. 
In response to the aforementioned issues and on the basis of the existing research, the present paper attempts to expound on the design and publication of customized iBooks Author (hereinafter referred to as iBA) CI course-books and to demonstrate that this kind of books is learner-friendly, interactive and evaluation-oriented with distinctive features of the age of Big Data.

\section{The Call for New CI Course-Books in the Age of Big Data}

Along with the spread of international language teaching methodologies in China, traditional CI teaching has been improved. Nevertheless, advanced teaching methods, subjected to the cumbersome publication and time-consuming selection of suitable teaching materials, are often put into practice in old-fashioned forms. In particular, the urgent need in the talent market for more qualified conference interpreters makes relatively outdated CI course-books loom larger. In order to suit the market, with some classes having as many as 30 students, Chinese institutions of higher learning have to enlarge the enrollment for their graduate programs of Master of Translation and Interpreting (hereinafter referred to as MTI). However, to ensure high teaching caliber, the class size must be small; moreover, consecutive interpreting classes should have no more than 15 students and simultaneous interpreting ones no more than 6 [7], otherwise there will be no time in class for teachers to appraise their students' performance and for students to form peer- and self-assessment. In summary, the CI teaching in China nowadays has become caught in a dilemma of expanding the class size or ignoring the market demand.

At present, the homogenization of the CI teaching in China has also come under the spotlight, which means that institutions of higher learning in different regions and at different levels set the same or similar teaching aims for their MTI programs. This problem results from the faculty structure that mainly involves untrained teachers and the dearth of appropriate CI course-books. In addition, the practice of reducing semester hours of MTI programs now in China runs counter to the fact that CI skill development requires a large amount of training in class, and it seems insoluble as yet. Extracurricular CI self-learning, consequently, has turned necessary, even mainstream. Such being the case, there has been increasing call for new CI course-books that are designed as simulators with a good deal of teaching resources and interactive teaching methods through which CI self-learning is possible.

In view of the above-mentioned facts, the Chinese academic world of foreign language teaching should design customized omnimedia CI course-books on the basis of multidimensional and synergetic innovation. More specifically, the teaching materials should be representative and varied selections that are appropriate for learners at various levels and with various learning goals; besides, they should enable the learners to assess their own performance and facilitate the interaction between teachers and their students by constantly providing the feedback on learning and formulating further teaching plans. At the moment, applying electronic course-books to the Chinese CI teaching with the aid of modern technologies is at the top of the agenda.

\section{The Modern Philosophy of Compiling CI Course-Books}

The CI course-books are of self-evident importance as they are expected to be compiled according to a philosophy that influences both the construction of the books themselves and the teaching practice. Thus, "careful consideration should be given to whether the course-books will conduce to the learners' self-learning, cooperative learning and exploratory learning, and whether the teaching resources are integrated in accordance with the learners' intellectual architecture" [8]. In this regard, the content of the CI course-books should focus on the learners' independent learning, and should be arranged in order of difficulty and in conformity with the learners' cognitive patterns and the ways that the learners think when interpreting and that their cognitive skills improve. To summarize, modern CI course-books should be more self-learning-driven by placing more emphasis on helping the learners develop their own learning strategies as a way to achieve the multidimensional interaction between teachers and their students, or students and their fellows.

\subsection{The Forming of the Mode of Self-Learning}

As things stand, Chinese CI teachers now have switched from traditional instructors to the facilitators, learners, discoverers, guides and organizers of the modern teaching, and have enhanced the students' independent learning by assisting them in structuring their own intellectual architecture and ensuring that they assimilate the knowledge. As the self-formed mode of independent learning and fragmented learning are gaining popularity with the technological advance in the age of Big Data, students are playing a dominant role in the CI teaching, and there are more teacher-student interaction in class and more self-learning practice after class. Arguably, China's CI learning is aiming at jumping out of the classroom to embrace the self-formed mode of independent learning.

In the age of Big Data, the compilers of new CI course-books should see to it that their philosophy of compilation can be justified by the "crowdsourcing research pattern" whose foundation is "the fourth paradigm" put forward by James Nicholas Gray so as to promote the learners' independent learning and sense of being-for-itself. In that case, the course-books will give as much prominence to professional, customized CI skill development and practice as possible and seek to exclude irrelevant information; furthermore, they will contain materials and accompanying glossaries and background information from real interpreting conditions and a wide range of fields of politics, diplomacy, economics, culture, technology and law, and will arrange these materials in order of the accuracy of pronunciation, the speed 
of speech and the lexical difficulty. The ideal CI course-books should set attainment targets for their users, and should provide the basics of CI, learning strategies, training resources, quality and competence assessment, demonstration as well as feedback; they should phase in skill development courses, which means that the pre-training competence assessment, introduction of background information, preparations for interpreting, practice, performance evaluation and proposing solutions to the negative feedback will be completed in stages; additionally, they should act as simulators through which the learners are allowed to develop relevant communicative behaviors and strategies, and then to practice interpreting when being exposed to real interpreting conditions.

\subsection{The Development of Countermeasure Awareness of CI}

In respect of CI strategies, the new course-books are expected to raise the learners' countermeasure awareness. For simultaneous interpreting countermeasures, they consist of delayed response, reconstruction of the speech according to the context and reference to fellow interpreters and materials handy in the listening comprehension stage; for preventive measures, they include note taking, the change of ear-voice span (EVS), the segmentation of sentences and the change of the order of the things enumerated; for reconstruction measures, they, in addition to the above-mentioned ones in the listening comprehension period, deal with the use of hypernyms and vague expressions, the explanation or paraphrase of the speech, the repetition of particular nouns or terms, decoding, and informing the listeners of the obstacles to your interpreting and the omission of certain information. On that score, the development of countermeasure awareness of consecutive CI focuses upon the expression, active listening and analyzing, memorization, note taking, reconstruction of information, self-monitoring and distribution of attention while that of simultaneous CI lays more stress on the expression, distribution of attention, EVS, anticipation, reconstruction of information, self-monitoring and stress management.

Specifically speaking, the new CI course-books are supposed to give effective guidance on interpreting practice that represents the findings of all the available literature on CI. With this prerequisite in place, the CI learners are able to spare some cognitive energy to learn other necessary skills if they have repeatedly practiced and hence internalized those already acquired; moreover, many CI leaners and trainers tend to break down the course loads when confronted with difficult skills.

\section{4. iBA: An Efficient Instrument for Designing and Publishing $\mathrm{CI}$ Couse-Books}

In the light of the growing demands for new, suitable CI course-books and more qualified conference interpreters in the age of Big Data, traditional CI course-books in the form of texts + tapes or CDs have come to the verge of being obsolete on account of their less informativeness, cumbersome publication, slow updating and the inevitable involvement of cassette or CD players. As a consequence, electronic books, one reproducible form of the mass media that allows texts, pictures and sounds to be recorded in magnets, light and electric current and to be readable on computers or other electronic devices, have emerged for their times.

As an e-book authoring application designed by Apple Inc., iBA can create books online and publish them in the Apple iBooks Store. With iBA, many aspects of a document may be edited in "what you see is what you get" fashion, including text, fonts, colors, foreground and background images, interactive widgets, and charts; besides, tables of contents and glossaries may be managed with some automation.

When using iBA, users will be introduced to the pleasures of the interactive reading on Mac or IOS terminals during which galleries, videos, sounds, 3D images, mathematical expressions and more will be displayed or played on the screen. They can also preview the books at any time when compiling them, and can publish the finished products for which they can apply for an International Standard Book Number (ISBN) in iBooks Store for chargeable or free download. Drawing on the efficiency and advantages of iBA, users are thus capable of concentrating all their efforts on compiling the content in scientific ways that conform to their cognitive patterns.

\section{The Features of the iBA CI Course-Books}

As mentioned earlier, traditional CI course-books in paper form are updated at an unsatisfactory rate and less informative. In contrast, iBA ones may well overcome these disadvantages by creating an immersive atmosphere and engrossing visual effects with texts, pictures, videos, sounds, 3D images, interactive interfaces and paralanguage, and they have generated the mode of CI self-learning and a new outlook on the CI teaching in the age of Big Data by lending a fresh perspective to the compilation of CI course-books. The authors of the present paper select the teaching materials in a professional view, and compile a series of iBA CI course-books with a forward-looking philosophy to boost CI skill development. Having redefined the role of CI electronic course-books after being put into use, these newcomers internalize the concept of "learner-friendliness" and underline that of "interaction - independence" with its quality teaching resources and ever-updating evaluation system.

\subsection{The Internalization of the Concept of "Learner-Friendliness"}

The readers will be offered a unique reading experience by the iBA CI course-books when turning the pages or scrolling the sidebars to read the content, for they can choose between reading one page at a time and two pages in the landscape orientation. They can also switch the books to the full screen mode to avoid distractions like pop-ups or to the night mode to 
carry out healthier reading.

The iBA CI course-books are accompanied by glossaries whose words are all highlighted in the texts for easy reference, and these technical or special words can be translated by the built-in dictionaries, or explained by the readers through annotations. To be beginner-friendly, the course-books play videos at a low speed, and insert blanks in between sense groups to save the users from being distracted by clicking pause when they need to stop to marshal their thoughts and interpret in order that they will develop a sense of information unit.

In the section of simultaneous interpreting practice, the learners are allowed to make self-assessment as the audio signals of the source and target languages are recorded on different tracks. "Assuming Conference Interpreting is mainly a skill, very much like one of the more difficult sports, performed mainly by the interpreter's brain, it becomes important to realize that the most difficult exercises can only be performed by the interpreter if he can draw upon a solid reserve of automatic reflexes which allow him to free his mind for those parts of the interpretative process which need his fullest attention" [9]. Taking this fact into account, the learning materials of the iBA CI course-books are graded according to the difficulty and classified according to the specialization in a pull-down menu, and they can be previewed or reviewed since the tables of contents, glossaries, widgets, main texts, and more have already been built in to automatically take advantage of VoiceOver (a screen reader built into Apple Inc.'s macOS, iOS, tvOS, watchOS, and iPod operating systems) technology. In addition, these course-books can be played through wired or wireless connection to the multimedia operating systems in the classrooms, which shows their learner-friendliness in a more typical way.

\subsection{The Integration of Teaching Materials}

Conceptualized as a problem-solver in the age of Big Data, the iBA CI course-books are informative, non-structured (in terms of their pictures, audios and videos) and up to date. For example, they will highlight the key words and display relevant background information to enliven the interpreting practice; they will play videos instead of audio files when the practice begins to help the learners perform better as they will have the chance to lip-read and interpret the paralanguage such as the facial expressions, gestures and other body movements of the speakers; they will also present the learners with subtitles if needed as a way to correct the possible mishearing.

When the compilation is accomplished, the iBA CI course-books can be published and downloaded in iBooks Store, or they can be read by the learners on a trial basis. They can also be exported in the forms of text, PDF or iBooks (the extension is ".iba") and shared on iTunes $U$ so that they can be used on non-Mac and non-IOS devices. Apart from that, those already downloaded will be updated automatically with the learners' prior knowledge as soon as a new version is introduced. Therefore, the above-mentioned features of the
iBA CI course-books can simplify the publication and ensure the timeliness of the learning materials, which obviously cannot be rivaled by traditional CI course-books.

\subsection{The Underlined Concept of \\ "Interaction-Independence"}

The new CI course-books in the age of Big Data should contribute to the independent construction of the learners' intellectual architecture because independent learning is crucial to gaining confidence and independence-consciousness. More specifically, they should "encourage the learners' active participation in the interpreting practice to foster communicative skills and strategies and bring about the independence of learning to a certain extent by providing authentic materials and creating real interpreting conditions" [10]. On this point, the iBA CI course-books add Multi-Touch (a technology that enables a surface to recognize the presence of more than one point of contact with the surface) functions to the content through widgets. They bring the readers swipe-friendly photo galleries, animations that burst off the pages, scrolling sidebars that offer possible translations for reference, Pop-Over (a container-type graphical control element that hovers over its parent window and blocks any other interaction until it is selected) widgets that present the background information for an element of surprise, 3D objects that give entertaining and interactive introductions of relevant concepts or theories, and hypertext links that are connected to online encyclopedias.

When the learners read the iBA CI course-books on IOS terminals, they can highlight the words by swiping through the screen; if they touch the highlighted parts, they can change the colors and add underscores or annotations; if they want to store these key words for future retrieval, they can also open Notes (a note-taking app available on IOS operating system) through the pop-up control panel to fulfill that. As to the interaction, the functions of Keynote (a piece of presentation software developed by Apple Inc.) and PowerPoint have been integrated into the iBA CI course-books so that the learning will not be monotonous.

\subsection{The Improved Evaluation System}

The iBA CI course-books allow teachers to evaluate their students' performance and students to make self-assessment from four aspects, namely the degree of coherence and reliability, the degree of faithfulness, the way of interpreting and the wording [11]. With this evaluation system and other widgets, the users will be presented with the evaluation results and solutions to the negative feedback after typing in their answers to the questions during the practice.

Moreover, the learners can share the scripts and possible translations of the learning materials with others, and in this way they are able to cooperate in interpreting and to form peer-assessment to their mutual advantage. They can make key content cards, note cards and word lists to create a databank through which they can test themselves at any time, or they can share these files on other social media or computer 
applications to let their instructors know about their progresses; in turn, the instructors can pace their teaching accordingly to produce effectual teacher-student interaction in the self-formed mode of independent learning.

\section{The Application of the iBA CI Course-Books: The Results of the Questionnaires in Two Chinese Universities}

The iBA CI course-books compiled by the authors of the present paper are designed on the basis of the theories of cognitive science, psychological linguistics and translatology. With the benefit of advanced teaching methods, they can represent real CI conditions to pragmatically promote the interpreting practice, and are conducive to customized, professional CI skill development on the strength of the scientific evaluation system in ways that stimulate independent learning.

"After years of theoretical discussion, Chinese scholars of foreign language teaching have agreed that CI learning equates to the development of communicative skills and that CI classes should subordinate improving the foreign languages to improving the $\mathrm{CI}$ techniques; as a result, various kinds of CI course-books and teaching methodologies are emerging in an endless stream. But be that as it may, there is still a lack of the research on the reform of the learning patterns and the learning performance that scientifically develops a workable teaching mode and specifically brings the theories into practice" [12]. Basing the philosophy of compiling this series of iBA CI course-books on their understanding of the current state of China's CI teaching and on some empirical evidence, the authors of the present paper, with the principle of putting the learners first, strive to bring the potential of advanced teaching methods and teaching resources into full play and to make the best use of quality learning materials in the CI teaching by conducting the research on the learning performance in the teaching practice after careful re-examination of the relationship between the CI teaching and learning.

"Course-books are special in the foreign language teaching practice in China, for they are central to pursuing the syllabuses, organizing teaching activities and acquiring relevant knowledge, skills and learning strategies" [13]. Considering that, it is essential to evaluate the course-books before they are put into use; furthermore, "effective evaluation depends on asking appropriate questions and interpreting the answers to them" [14]. In the effort to collect the feedback on the iBA CI course-books and to remedy their deficiencies if there are any, the authors of the present paper justifiably design questionnaires in which there are 8 items, namely "the arrangement of the learning materials", "the utility of the learning resources", "the quality of the learning materials", "the performance of the evaluation system", "the effectiveness of the interaction", "the usefulness of the homework", "the progress of your CI skill development" and "the overall user experience of the course-books", and request 58 candidates for the degree of MTI in two Chinese universities to fill in them. In the 57 valid questionnaires, the responses are graded from 1 (not at all satisfied) to 5 (very satisfied) and are listed in Table 1 .

Table 1. The Results of the Questionnaires in Two Chinese Universities.

\begin{tabular}{|c|c|c|c|c|c|c|}
\hline Item & 1 & 2 & 3 & 4 & 5 & The proportion of " 4 " and "5" \\
\hline The arrangement of the learning materials & 0 & 0 & 3 & 16 & 38 & $94.7 \%$ \\
\hline The utility of the learning resources & 1 & 3 & 9 & 22 & 22 & $77.2 \%$ \\
\hline The quality of the learning materials & 0 & 1 & 6 & 15 & 35 & $87.8 \%$ \\
\hline The performance of the evaluation system & 1 & 3 & 10 & 17 & 26 & $75.4 \%$ \\
\hline The effectiveness of the interaction & 1 & 1 & 10 & 22 & 23 & $78.9 \%$ \\
\hline The usefulness of the homework & 0 & 1 & 8 & 25 & 23 & $84.2 \%$ \\
\hline The progress of your CI skill development & 0 & 0 & 6 & 16 & 35 & $89.5 \%$ \\
\hline
\end{tabular}

The results show that the proportion of " 4 " and " 5 " of "the overall user experience of the course-books" is $93 \%$, and some other teachers and students also give positive feedback on the iBA CI course-books in the interviews with them. In terms of professional opinions, these new course-books receive favorable comments from a panel of experts on course-book compilation and foreign language teaching, which reflects the progressive philosophies of formulating the teaching modes, learning strategies, teaching methods and two-way evaluation embodied in them.

\section{Conclusion}

In the age of Big Data, the emergence of e-books has overhauled the CI learning in China by providing the learners with far more bilingual information and an interactive reading mode in accordance with their cognitive patterns. "To meet the market demand for more qualified conference interpreters and to offset the defects of the traditional CI course-books, the heterogeneous omnimedia CI course-books should simulate real interpreting conditions and promote interactive $\mathrm{CI}$ learning for better independent learning" [15]. Therefore, the present paper elaborates on the modern features of the iBA CI course-books with the prominence to the development of the self-formed mode of independent learning and CI learning strategies after introducing relevant background information. The authors of the present paper assess the performance of the iBA CI course-books in two Chinese universities through questionnaires and interviews, and prove that this new kind of CI course-books is a helpful incentive in professional, 
customized CI skill development and practice due to its sound theoretical basis, advanced teaching methods and scientific evaluation system.

\section{References}

[1] Lan, H. J. (2015). The Translation Teaching-The Key to Disciplinary Development of Translatology in the New Era. China University Teaching 6, 32-37.

[2] Tao. Y. L. (2017). Translation Textbook Compiling in the Perspective of the Extended Translatology. Shanghai Journal of Translators 6, 83-88.

[3] Yao, B. (2017). The Compilation of MTI Interpreting Course-Book: Problems and Expectations. Shanghai Journal of Translators 6, 74-78.

[4] R. Setton and A. Dawrant, Conference Interpreting: A Complete Course/A Trainer's Guide. Amsterdam: John Benjamins, 2016.

[5] Liu, J. (2017). Teaching Interpretation with a Multimodal Interpreting Corpus. Technology Enhanced Foreign Language Education 2, 9-14.

[6] Zhao, C. H. (2017). Development Principles and Countermeasures of Profession-Oriented Interpreting Textbooks. Technology Enhanced Foreign Language Education 4, 60-65.

[7] C. S. Yang, Interpretation Studies. Beijing: China Translation \& Publishing Corporation, 2005, pp. 34.
[8] Xiang, G. X. (2005). From Traditional Teaching Materials to Electronic Ones. China Information Technology Education 5, $8-10$.

[9] W. Weber, "Improved ways of teaching consecutive interpretation," in The Theoretical and Practical Aspects of Teaching Conference Interpreting, L. Gran and J. Dodds, Eds. Udline: Campanotto Editore, 1989, pp.162.

[10] Wang, S. L. (2006). The Present Problems for Evaluating College English Teaching Materials and the Solutions to Them and the Appraisal of Cunningsworth's Evaluation System. China University Teaching 5, 57-60.

[11] A. Schjoldager, "Assessment of simultaneous interpreting," in Teaching Translation and Interpreting 2. Insights, Aims, Visions, C. Dollerup and V. Appel, Eds. Amsterdam: Benjamins, 1996, pp.190.

[12] Cai, X. H. (2008). A Performance-Keyed Study of an Interactive Model for Teaching Interpreting. Chinese Translators Journal 4, 45-48.

[13] Qian, Y. (1995). The Introduction of a Checklist of Teaching Materials Evaluation. Foreign Language World 1, 17-19.

[14] A. Cunningsworth, Choosing Your Coursebook. Shanghai: Shanghai Foreign Language Education Press, 2002, pp.vi.

[15] Xu, W. S. (2014). The Synergetic Innovation of the Design and Publication of Omnimedia Conference Interpreting Course-Books. Translation Forum 1, 44-48. 